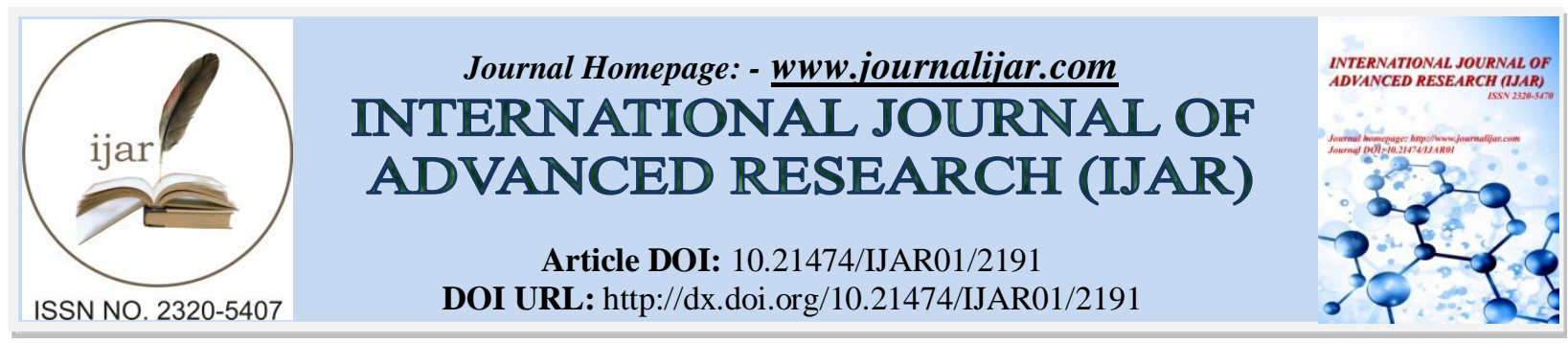

RESEARCH ARTICLE

\title{
ASSESSMENT ON WORK RELATED CARDIOPULMONARY SYMPTOMS AS INDICATORS OF COBBLESTONE WORKERS MORBIDITY IN ADDIS ABABA.
}

Hailemariam Mamo (MSc) ${ }^{1}$ and Yoseph A. Mengesha (MD, PhD) ${ }^{2}$.

1. Department of Biological Sciences, Dire Dawa University, Dire Dawa, Ethiopia

2. Department of Physiology, School of Medicine, College of Health Sciences, Addis Ababa University Addis Ababa, Ethiopia.

\section{Manuscript Info}

Manuscript History

Received: 27 September 2016

Final Accepted: 30 October 2016

Published: November 2016

Key words:-

Cobblestone, Quarry, Chiseling, Dust

Exposure, Cardio-respiratory symptoms

\section{Abstract}

Cobblestone work has become a good job opportunity in Ethiopia; However workers are exposed to dust during excavating, cutting, drilling, handling, loading,transporting,chiseling and paving activities. Stone dust exposure has effect on the cardio-respiratory, liver and kidney functions with its associated symptoms as it contains metals and other substances risky for human health. The present study was designed to assess work related cardiopulmonary symptoms as indicators of cobblestone workers morbidity in Addis Ababa. Comprative cross-sectional study and random sampling was applied on chiseling and quarry workers exposed for one and above years. Standard questionnaire, structured interview and observational checklist were used for data collection. The study showed higher prevalence of cardio-respiratory symptoms and illness. The test of proportion (p) shows, there was an association between dust inhalation and the occurrence of respiratory symptoms and diseases. The strength of association was explained by odd ratio (OR), relative risk (RR) and attribute risk (AR) which compare the symptoms difference between exposed groups and controls as well as between subgroups. The chisquare test indicated presence of significantly higher prevalence of the cardio-respiratory symptoms. From the present study, it could be concluded that dust emission during cobblestone preparation adversely affects the cardio-pulmonary wellbeing of workers. It is recommended that further studies should be conducted on many workers to make standing decisions and regulations. Regular inspection should be carried out. There should be full co-operation among the competent authority, research institutions workers and occupational health professional.

Copy Right, IJAR, 2016,. All rights reserved.

\section{Introduction:-}

Although, cobblestone projects constitute an important construction sector in Ethiopia, workers are exposed to dust and physical injuries during excavating, cutting, drilling, handling loading, transporting, chiseling and paving activities. Stone quarry workers are at increased risk of lung and lung function effects because of their occupational exposure to silica dust [1-4]. Many studies show occupations involving stone materials increase chance of stone 
dusts exposure which has adverse effects on health [5-6]. Inhaling stone dust causes the formation of lumps and fibrous scar in the lungs as the dust able to reach the deepest areas of the lungs alveoli [5].

Numerous studies have linked particle pollution exposure to increased cardio-respiratory symptoms [7]. Symptoms such as irritation of the airways, coughing, chronic bronchitis, respiratory cancers, chronic obstructive pulmonary disease (COPD), occupational asthma, pneumoconiosis and breathing difficulty through decreased lung function are the common diseases among others. Irregular heartbeat, non-fatal heart attacks and toxic effects by absorption of the toxic material into the blood could be caused by dust particles exposure [8]. Such injuries and diseases impose enormous costs and impoverish workers and their families' productivity and work capacity and dramatically increase health care expenditures [9].

Exposure to stone dust causes lung diseases which are associated with cardiovascular complications [10]. There is a possible association between occupational exposure to dust and ischemic heart disease $[1,11]$. Fine dusts has capability to evade the protective barrier lining (epithelium) of the airways. The dust enters to the underlying tissue then to the circulation. It means the toxicity of ultrafine particles may not be limited to the airways but may involve the cardiovascular system, liver, brain, and kidneys [5,12]. Chest pain at physical exertion, shortness of breath, feeling tired or weakness, tripping or racing heart, cold hands or feet, cough, phlegm, being awakened by breathing problems, wheezing, and common cold and sign in avoidance of activities have also been discussed in some studies conducted on dust exposed individuals [13].

\section{Materials and Methods:-}

The study was conducted on the cobblestone (quarry and chiseling) workers in Addis Ababa. Comparative crosssectional study method was applied involving 82 chiseling and 73 quarry workers exposed for more than a year. Proportional number of non exposed groups was selected from Addis Ababa University non-smoking normal students and checked to fulfill the inclusive criteria. Participants' full consent and free will was obtained. Standard questionnaire, structured interview and observational checklist were used for data collection. Inclusion and exclusion criteria were explained exhaustively before administration of the procedures.

Inclusion Criteria: Male and female workers who have been directly involving in quarry and chiseling works for one year and above were included in the study.

Exclusion Criteria: Workers with abnormalities of vertebral column and thoracic cage, anemia, diabetes mellitus, hypertension, pulmonary tuberculosis, bronchial asthma, chronic bronchitis, emphysema and other respiratory diseases were excluded. Those who had undergone abdominal or chest surgery were not allowed to participate in the study. Smokers and workers who stayed at work for less than a year were excluded

\section{Result:-}

The test of proportion (p) shows that, there is an association between dust inhalation and the occurrence of respiratory symptoms and diseases (table 1). The strength of association was explained by odd ratio (OR), relative risk (RR) and attributive risk (AR) which compare the symptoms difference between exposed groups and controls as well as between subgroups.

Table 1:- Prevalence of Cardio respiratory symptoms of exposed and controls including RR,AR and OR with 95\% CI. 


\begin{tabular}{|l|l|l|l|l|l|l|l|}
\hline No. & Variables & $\begin{array}{l}\text { Exposed } \\
(\mathrm{n}=155)\end{array}$ & $\begin{array}{l}\text { Controls } \\
(\mathrm{n}=151)\end{array}$ & RR & AR & OR & $95 \%$ CI for OR \\
\hline $\mathbf{1 .}$ & Cough & $93(60 \%)$ & $42(27.8 \%)$ & 2.16 & 0.32 & 3.89 & $(2.41,6.28)$ \\
2. & Phlegm & $71(45.8 \%)$ & $48(31.8 \%)$ & 1.44 & 0.14 & 1.81 & $(1.14,2.89)$ \\
3. & Breathlessness & $110(71 \%)$ & $52(34.4 \%)$ & 2.06 & 0.37 & 4.65 & $(2.87,7.54)$ \\
4. & Wheezing & $85(54.8 \%)$ & $44(29.1 \%)$ & 1.88 & 0.26 & 2.95 & $(1.84,4.74)$ \\
$\mathbf{5 .}$ & Chest tightness* & $119(76.8 \%)$ & $50(33.1 \%)$ & 2.32 & 0.44 & 6.68 & $(4.03,11.05)$ \\
6. & Chest pain* & $114(73.5 \%)$ & $40(26.5 \%)$ & 2.77 & 0.47 & 7.72 & $(4.64,12.82)$ \\
\hline
\end{tabular}

* Chest tightness and chest pain signify both respiratory and cardiac problems.

In the exposed groups, these cardio-respiratory symptoms were analyzed in both quarry and chiseling groups separately. The prevalence of the symptoms varied between the two separate subgroups. The odd ratio in each comparison shows certainty how much higher prevalence occurred in a group compared within $95 \%$ confidence interval (table 2).

Table2:- The prevalence of cardio-respiratory symptoms according to similar exposure groups (SEGs) i.e. chiseling and quarry workers.

\begin{tabular}{|l|l|l|l|l|l|l|l|}
\hline No. & Variables & $\begin{array}{l}\text { Chiseling } \\
(\mathrm{n}=82)\end{array}$ & $\begin{array}{l}\text { Quarry } \\
(\mathrm{n}=73)\end{array}$ & RR & AR & OR & CI 95\% for OR \\
\hline 1. & Cough & $52(63.4 \%)$ & $41(56.2 \%)$ & 1.27 & 0.072 & 1.35 & $(0.71,2.58)$ \\
2. & Phlegm & $38(46.3 \%)$ & $33(45.2 \%)$ & 1.15 & 0.011 & 1.05 & $(0.56,1.97)$ \\
3. & Wheezing & $39(47.6 \%)$ & $46(63 \%)$ & 0.85 & -0.154 & 0.53 & $(0.28,1.01)$ \\
4. & Breathlessness & $62(75.6 \%)$ & $48(65.8 \%)$ & 1.29 & 0.098 & 1.61 & $(0.80,3.25)$ \\
5. & Chest tightness & $62(75.6 \%)$ & $57(78.1 \%)$ & 1.09 & -0.025 & 0.87 & $(0.41,1.84)$ \\
6. & Chest pain & $69(84.1 \%)$ & $45(63 \%)$ & 1.50 & 0.211 & 3.12 & $(1.83,5.30)$ \\
\hline
\end{tabular}

* Chest tightness and chest pain signify both respiratory and cardiac problems

Acute effects of dust after immediate exposure were assessed as acute respiratory symptoms by providing questionnaire to evaluate the prevalence of supposed acute or immediate respiratory symptoms which might occur after working for some hours in every working day. Both subgroups of cobblestone workers were analyzed separately (figure 1). 


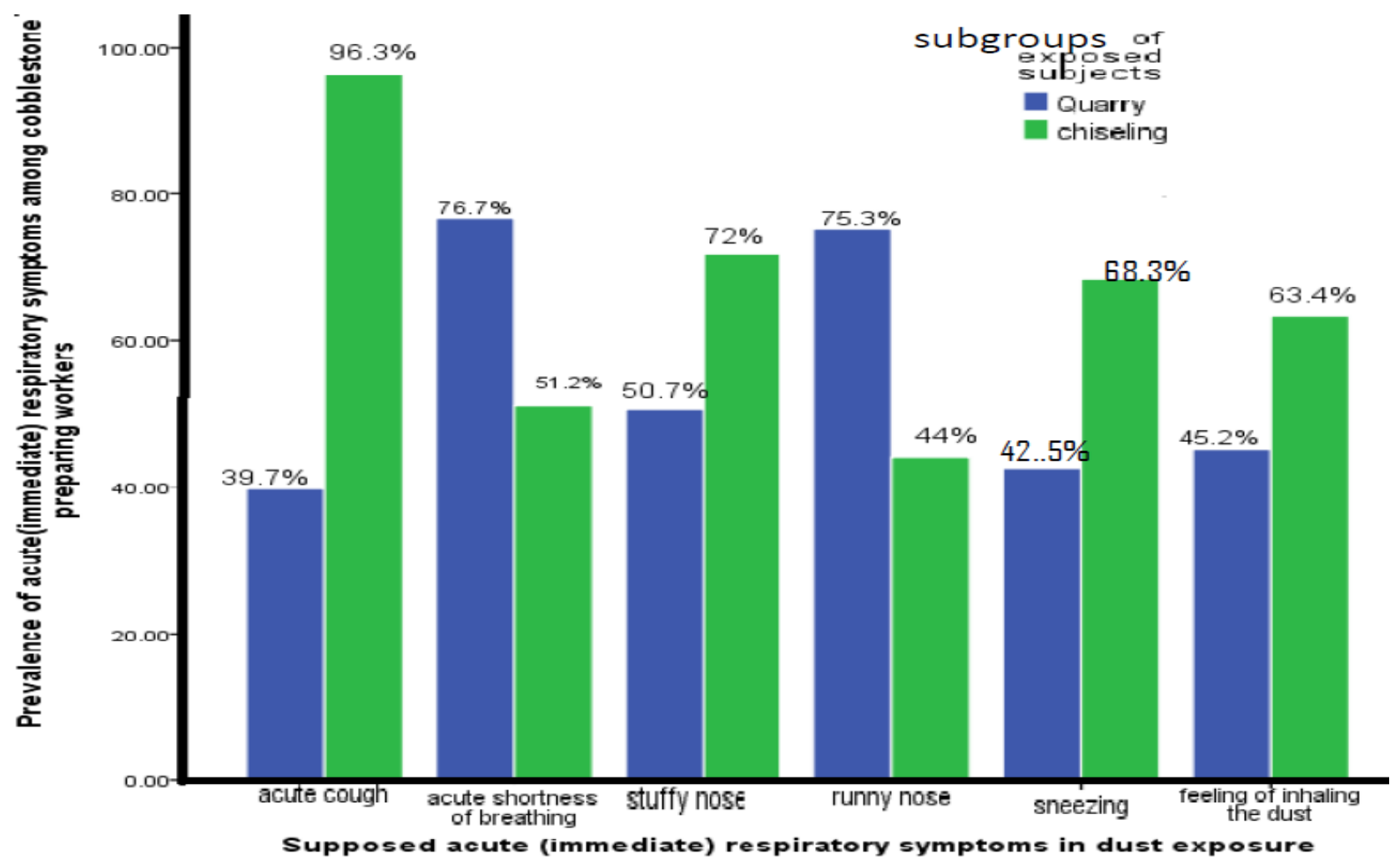

Discussion:-

Figure 1:- Prevalence of the acute or immediate respiratory symptoms

The stone cutting and crushing workers are exposed to stone and other related dusts which could cause different kinds of cardio-respiratory diseases $[14,15]$. The respiratory problems caused by dust exposure include chest pain, occasional cough, occasional shortness of breath and wheezing. The inhalation of dust over periods of time leads to proliferation of alveolar epithelium and fibrotic changes in lungs [1, 14, 16-17]

In the present study, the test of proportion (p) shows there is an association between stone dust inhalation and the occurrence of respiratory disease symptoms. The prevalence of cardio-respiratory symptoms was high in cobblestone workers than in controls.

The chi-square test indicates the presence of significantly higher prevalence of the cardio-respiratory symptoms as $\mathrm{OR}$ and its $95 \%$ confidence interval mentioned. About $60 \%(\mathrm{OR}=3.89, \mathrm{RR}=2.16, \mathrm{AR}=0.32)$ of exposed participants stated that they had experienced frequent cough. Symptoms which include Phlegm ( $11=45.8, \quad R R=1.44$, $\mathrm{AR}=0.14, \mathrm{OR}=1.81)$, breathlessness $(\mathrm{p} 1=71, \mathrm{RR}=2.06, \mathrm{AR}=1.88, \mathrm{OR}=4.67)$, wheezing $(\mathrm{p} 1=54.8, \mathrm{RR}=2.32, \mathrm{AR}=0.37$, $\mathrm{AR}=0.26, \mathrm{OR}=2.95)$, chest tightness $(\mathrm{P} 1=76.8, \mathrm{RR}=2.77, \mathrm{AR}=0.44, \mathrm{OR}=6.69)$ and chest pain $(\mathrm{P} 1=73.5, \mathrm{RR}=3.06$, $\mathrm{AR}=0.47, \mathrm{OR}=7.69$ ) were experienced by exposed subjects. The proportion of each claimed symptom was above two times higher in exposed participants than in controls except phlegm which was about one and half times higher. Only this shows how many times more likely exposed participants to become diseased relative (RR) to controls. The incidence of each symptom was highly attributable (AR) to dust exposure in cobble stone working sites. A number of studies confirmed [1,2-4] that, Stone quarry workers are at increased risk of lung and lung function effects.

Frequencies (proportions) of cardio-respiratory symptoms among control participants (p2) were lower than that of exposed groups ( $\mathrm{p} 1)$. Cough ( $\mathrm{p} 2=27.8)$, phlegm $(\mathrm{p} 2=31.8)$, breathlessness $(\mathrm{p} 2=34.4)$, wheezing $(\mathrm{p} 2=29.1)$, chest tightness $(\mathrm{p} 2=33.1)$, chest pain $(\mathrm{p} 2=26.5)$ were cardio-respiratory symptoms that they had been experiencing.

It is not clear on plausible mechanism and which fraction of particulate matter is responsible for the cardiovascular effects. One hypothesis [13] is probably, ultrafine particles deposited in the alveoli lead to increased blood coagulation. This mechanism operates either via pulmonary inflammation or via a direct action of those ultrafine 
particles on red blood cells leading to the sequestration of erythrocytes. An alternative hypothesis is that the cardiovascular effects are caused by alteration of the autonomic control of the heart. This theory is supported by epidemiologic studies on heart rate heart rate variability and arrhythmia. Changes in heart rate and heart rate variability were found among elderly subjects on days with elevated levels of particulate matter. These findings are supported by the results of several toxicological studies $[13,18]$.

Dust particles induce pulmonary and systemic inflammation, accelerating atherosclerosis and altering cardiac autonomic function [19]. Various central and autonomic mechanism as well as mechanical (heart) and hemodynamic adjustments are triggered in response to variation of breathing patterns thereby causing both tonic and phases changes in cardiovascular functioning. Several hypotheses have been proposed. In view of that, cardiac autonomic control could be disrupted directly by inhaled particulates through sympathetic stress response and imbalance of cardiac autonomic control [20].

Cobblestone workers were observed and classified according to similar exposure groups (SEGs), i.e. chiseling and quarry workers. Thus, cardio-respiratory symptoms were analyzed in both quarry and chiseling groups separately. The proportion of workers who have had the symptoms was greater in chiseling workers. The rate of positive response of chiseling workers on cough $(63.4 \%)$, phlegm $(46.3 \%)$, breathlessness $(47.3 \%)$ and chest pain $(84.1 \%)$ were higher than the quarry workers' proportions which were $56.2 \%, 45.2 \%, 65.8 \%, 63 \%, 58.9 \%$ and $65.8 \%$, respectively. Rate of response for wheezing (63\%) and chest tightness (78.1\%) in quarry workers were higher that of that chiseling workers which were $47.6 \%$ and $75.5 \%$, respectively. The strength of association was explained by odd ratio (OR), relative risk (RR) and attributive risk (AR) which compare the symptoms difference between subgroup (SEGs). The odd ratio in each comparison shows the certainty on how much higher prevalence occurred in a group compared within $95 \%$ confidence interval of calculated values.

The prevalence of the symptoms variation between the two subgroups (SEGs) could have possible reasons. The chiseling workers were mostly working in shade while quarry workers work in open space with better ventilation. This condition could account for the greater prevalence of symptom among chiseling workers. Previous published work [21] explained that air movement extent has a great deal of variability effect of dust on health. Similar exposed groups (SEGs) in enclosed and air controlled work environments typically experience lower air movement compared with SEGs working outdoors. Thus, it increases the dust concentration which in turn increases the potential for risk of inhaling much more respirable dust and quartz. The other factor probably could be the proximity of workers respiratory parts to the stone being chiseled producing various size dust particles. It might make sense that the nature of chiseling work activities requires intense contact with stones increasing the probability of higher exposure.

Other likely reason could be the level of work load. The quarry workers have had machinery support while the chiseling workers don not. Therefore, the higher the workload the higher the breathing rate so that more dust is inhaled. Thus, tasks involving heavy physical work will entail greater dust inhalation because the amount of dust inhaled depends on the lung ventilation rate [21].

The respiratory problems caused by dust exposure include chest pain, occasional cough, occasional shortness of breath and wheezing. The inhalation of dust over periods of time leads to proliferation and fibrotic changes in lungs. Severity depends on several factors including the chemical nature, physical state of the inhaled substance, the size, concentration of the dust particles, the duration of exposure and individual susceptibility. Proximity to sensitive receptors, prevailing wind direction, speed and nature of works topography influence the level of impact [22].

Based on similar exposure groups (SEGs) both subgroups of cobblestone workers were assessed separately (see figure 1). About $39.7 \%$ of participants from quarry and $96.3 \%$ of chiseling workers stated that they had experienced acute cough after working for some hours in every working day. This indicates that the chiseling workers were very highly exposable to the dust. Respondents among quarry workers claimed that shortness of breathing (76.7\%), stuffy nose $(50.7 \%)$, runny nose $(75 \%)$, sneezing $(42.5 \%)$ and feeling of dust inhaling $(45.2 \%)$ were symptoms they had noticed while they were work. The chiseling workers were also reported that they had suffered from shortness of breathing (51.2\%), stuffy nose (72\%), runny nose (44\%), sneezing (68.3\%) and feeling of dust inhaling (63.4\%).

The study results show immediate (acute) shortness of breathing and runny nose were more prevalent in quarry workers than in chiseling workers. The chiseling workers have had higher possibility of sensing the dust being inhaled. It could probably be a result of either higher proximity or greater amount and concentration of dust 
emission. Similar study showed that sweepers in India had had more significant respiratory symptoms like sneezing, stuffy nose, running nose and shortness of breath after sweeping for some hours [23].

\section{Conclusion and Recommendation:-}

The study has identified the symptoms of dust exposure on the cardio-respiratory functions. From the present study, it could be concluded that dust emission during cobblestone preparation adversely affects the cardio-pulmonary function of the workers. The protection of workers' health against the occupational hazards at the workplace should be the concern of all of those involved in the design, organization and performance of the work and the protection of workers' health. Early detection, prevention and intervention on diseases as well as improving the working environment are the main purposes of medical surveillance. It is recommended that further studies should be conducted on many workers to make standing decisions and regulations. Regular inspection should be carried out. There should be complete co-operation among the competent authority, research institutions workers and occupational health professional.

\section{References:-}

1. Dino Pisaniello, Michael Tkaczuk and Sharyn Gaskin (2013). Evaluation of Dust Inhalation Risk Factors A research study to reduce lung disease risks in SA quarries. Occupational \& Environmental Hygiene, Discipline of Public Health, School of Population Health, University of Adelaide.

2. Smilee Johncy, G Dhanyakumar, Kanyakumari, T (2013). Vivian Samuel. Chronic exposure to dust and lung function impairment. A study on female sweepers in India.

3. Ghotkar V.B., Maldhure B.R. and Zodpe S.P.( 1995). Involvement of Lung and Lung Function Tests in Stone Quarry Workers Indian Journal of Tuberculosis.; 42:155

4. Sangeeta Vyas.( 2012). A study of pulmonary function tests in workers of different dust industries International Journal of Basic and Applied Medical Sciences.; 2:15-21

5. Matt Loxham.(2013). Microscopic dust particles found in underground railways may pose health risk. Phys.org. University of Southampton..

6. AN Nwibo, EI Ugwuja, NO Nwambeke, OF Emelumadu, LU Ogbonnaya(2012). Pulmonary Problems among Quarry Workers of Stone Crushing Industria Site at Umuoghara, Ebonyi State, Nigeria. The International Journal of Occupational and Environmental Medicine. 3:178-185

7. Department of Environment and Conservation (2011) A guideline for managing the impacts of dust and associated contaminants from land development sites, contaminated sites remediation and other related activities..

8. Health and Safety Executive (HSE) (201). Work-related respiratory disease. Website: http://www.hse.gov.uk/statistics/index.htm published.

9. International Labour Organization (2013). The Prevention of Occupational Diseases. World Day for Safety and Health at Work..

10. Crystalline Silica exposure health hazard information. Informational fact sheets High lighting Occupational safety and health administrative OSHA U.S.A department of labor, 2002.

11. Mahdi Kargarfard, Reza Rouzbahani, Saber Rezanejad(3), Parinaz Poursafa(2009). The Effect of Air Pollution on Cardiorespiratory Performance of Active Individuals. ARYA Atherosclerosis Journal.; 5:2: 69-75

12. Zala Jenko Pražnikar1, Jure Pražnika(2011).The effects of particulate matter air pollution on respiratory health and on the cardiovascular System..

13. Tsun-Jen Cheng, Jing-Shiang Hwang, Peng-Yau Wang, Chia-Fang Tsai, Chun-Yen Chen, Sheng-Hsiang Lin, and Chang-Chuan Chan(2003). Effects of Concentrated Ambient Particles on Heart Rate and Blood Pressure in Pulmonary Hypertensive Rats. Environmental Health Perspectives.; 111:2

14. Shaikh Khurshid Anwar, Naeem Mehmood, Nasir Nasim, Marya Khurshid, and Bilal Khurshid.( 2013). Sweeper's lung disease: a cross-sectional study of an overlooked illness among sweepers of Pakistan. International Journal of COPD. 8:193-197

15. Smilee Johncy (201). Dust Exposure and Lung Function Impairment in Construction Workers. Journal of Physiol Biomed Sci. 2011;24:1: 9-13.

16. Mbbs Moeh Fracp(2011). Respiratory problems, Occupational and environmental exposures. Websites: http://www.racgp.org.au/afp/authorslist/h/ryan-f-hoy/. . Accessed on May 10, 2013.

17. Petr Brhel(200). Occupational Respiratory Diseases in the Czech Republic. Industrial Health.; 41:121-123 
18. Mashaallah Aghilinejad, Ali Naserbakht, ${ }^{2}$ Morteza Naserbakht, and Ghavamedin Attari(2012). Silicosis among Stone-Cutter Workers: A Cross-Sectional Study. National Research Institute of Tuberculosis and Lung Disease, Iran 11:2: 38-41

19. Barreiro T. Timothy J. and Perillow J. (2004) An approach to interpreting spirometry. American academy of physicians. vol. 69: 5

20. Duanping Liao1, Yinkang Duan1, Eric A. Whitsel2, Zhi-jie Zheng3, Gerardo Heiss Vernon M. Chinchilli1, and Hung-Mo ( Lin2003). Association of Higher Levels of Ambient Criteria Pollutants with Impaired Cardiac Autonomic Control: A Population-based Study Prevention and Health Promotion, Centers for Disease Control and Prevention, Atlanta,

21. Dino Pisaniello, Michael Tkaczuk and Sharyn Gaskin (2012). Evaluation of Dust Inhalation Risk Factors A research study to reduce lung disease risk in SA quarries. Occupational \& Environmental Hygiene, Discipline of Public Health, School of Population Health, University of Adelaide..

22. Canadian Centre for Occupational Health \& Safety (2012). What are the Effects of Dust on the Lungs? Website,.Accessed on October 30/5/13 PM.

23. Smilee Johncy.(2013). Acute Lung Function Response to Dust in Street Sweepers. Journal of Clinical and Diagnostic Research. Vol-7(10): 2126-2129 